Abstract

\title{
Centennial Challenges Program Overview: How NASA Successfully Involves the General Public in the Solving of Current Technology Gaps
}

Monsi C. Roman, Tony Kim, Janet Sudnik, Amy Sivak, Molly Porter, Rosaling Cylar, Dominique Cavanaugh and Kim Krome

The National Aeronautics and Space Administration (NASA) Centennial Challenges Program, part of the Space Technology Mission Directorate (STMD), addresses key technology needs of NASA and the nation, while facilitating new sources of innovation outside the traditional community. This is done by the direct engagement of the public at large, through the offering of Congressional authorized prize purses and associated challenges developed by NASA and the aerospace community and set up as a competition awarding the prize money for achieving the specified technology goal.

Prizes and challenges have long been used as a method to inspire people to advance technology. In 1761, John Harrison (a clock maker) solved the British maritime navigation challenge. In 1809, Nicolas Appert (a baker) solved the Napoleon challenge for food preservation. In 1927, Charles Lindbergh (a mail pilot) won the Orteig Prize by being the first to fly across the Atlantic Ocean. And in 2004, Burt Rutan (an aerospace engineer) won the XPRIZE Ansari challenge by being the first private entity to enter space twice within two weeks.

In 2005, the United States Congress amended the National Aeronautics and Space Act of 1958 to permit NASA to run challenges and to award prize money to United States Citizens or United States Entities. NASA was the first U.S. government agency to join the Prizes and Challenges community, launching its Centennial Challenges Program with the hope of engaging the public in finding solutions to technology problems of interest to the agency and the nation. Centennial Challenges is the flagship prize program for NASA which, according to the White House Office of Science and Technology Policy (OSTP) "leads the public sector in the breadth and depth of experience and experimentation with prizes and challenges."

The Program selects and develops challenges through wide consultation within and outside the Federal Government. NASA partners with either external, private, non-profit organizations or internal NASA programs to execute challenges. The Centennial Challenges Program selects managing organizations through the proposal requests process. NASA and external organizations enter into an Space Act Agreement (SAA). External managing organizations may obtain financial and in-kind support for the challenge from sponsors in the private and or public sector. The Program may also partner with other government agencies to enhance the opportunities of any single challenge.

In the past 11 years, Centennial Challenges has opened 18 challenges, covering technology areas including: propulsion, robotics, communications and navigation, human health, science instrumentation, nanotech, materials and structures, and aerodynamics. Of those 18 competitions, 12 have been executed, 11 with winners (teams that advanced technology as defined in the rules of the challenge). Fourty-four prizes totaling more than $\$ 7.2$ million have been awarded, and several new companies have been born in the private sector using those technology advancements. Two of those companies, Masten Aerospace and Flagsuit LLC now have contracts with the agency, bringing the technology full circle. 
In an effort to improve the design and execution of challenges, the program has begun a strategic evaluation of processes both internally and externally. Many changes have been made as these evaluations provide information that can improve the way to approach the use of prizes and challenges to augment the pool of technologies available to NASA and the nation. Improvements to the program include: Strong aligment with current Agency's technology needs; Improvement of competition design process and logistics to increase opportunities for success while maintaining the integrity of the challenge; early Partnering with subject matter experts (SME) inside and outside of the Agency to assure developments above and beyond State-of-the-Art; Identifying potential earth application of technologies; and Increasing the pool of challenge partners as well as competition participants. The program is in the process of defining specific metrics that would help evaluate the progress toward program goals.

As part of improving the program, a grant was awarded to a George Washington University to study the program and evaluate its efficacy in meeting the goals of attracting participants from diverse backgrounds and, advancing technology for NASA and the nation. Data and recommendations provided by the GWU team will be reviewed and, if possible, incorporated to improve the program's ability to meet those goals. Centennial Challenges will provide suggestions on team formation (the benefits of diverse backgrounds) as well as general guidance in a package provided at the start of new challenges. Centennial Challenges will continue to attend events that draw non-traditional participants, raising awareness of the program within new communities. After the challenge, participants will be provided information on potential paths to further develop their technologies and transition them into a NASA program - increasing the benefit to the agency as well as the participating teams. And finally, the program is making a concerted effort to track non-challenge activities that have been spurred by participation in the challenge such as publications, new job opportunities, and new businesses.

NASA's Centennial Challenge Program continues to push the boundaries of prizes and competitions by closing the fiscal year (FY) 16 after announcing two groundbreaking new competitions, completing/closing two successful multi-year challenges, and continuing one very successful challenge that will produce flight hardware. In addition, the program is working in the formulation of five new challenges that will be open over the course of the next two fiscal years. The space exploration technology gaps areas that the program targeted in FY16 ranged from the advancement in humanoids that one day might accompany humans on the surface of Mars to the development of vascularized tissue that could help make the journey to Mars safer for humans.

The focus of this paper is to provide insight into NASA's Grand Challenges Program, Centennial Challenges and how NASA technology objectives are being met with the help of non-traditional sources and the use of prize competitions. Stages for challenge development and execution will be discussed, as well as communication strategies. The Centennial Challenges Program values Innovation, Communication, and Opportunity. Centennial Challenges drives innovation by encouraging the participation from non-traditional sources in aerospace research and development; and inspiring invention by pushing technology boundaries and pursuing state-of-the-art technology solutions. The Program gets significant media attention, captures the public imagination, and engages people and communities. The Program also leverages challenge-derived technology advancement to further an identified NASA need, and enables competitors to develop and/or expand business models and business base. A summary of past Challenges, as well as Challenges in execution will be provided. Insight on some of the competitions in development will also be discussed. 